\title{
13C-nmr Spectroscopy to Monitor Sugars in Pith of Internodes of a sh2 Corn at Developmental Stages
}

\author{
V.M. Russo ${ }^{1}$ \\ U.S. Department of Agriculture, Agricultural Research Service, South Central \\ Agricultural Research Laboratory, POB 159, Lane, OK 74555 \\ J. Williamson, K. Roberts, and J.R. Wright \\ Department of Physical Sciences, Southeastern Oklahoma State University, \\ Station A, Durant, OK 74701
}

N. Maness
Department of Horticulture, Oklahoma State University, Stillwater, OK 74078

Additional index words. Zea mays, glucose, fructose, sucrose, HPLC, carbon-13 nuclear magnetic resonance spectroscopy

\begin{abstract}
Sugars move through stalks to be deposited in kernels in sweet corn (Zea mays L.). Concentrations of sugars in stalks change as plants pass through developmental stages. To follow such changes, carbon-13 nuclear magnetic resonance spectroscopy (C-nmr), a technology that can measure concentrations of sugars in tissues, was compared with analysis by high-performance liquid chromatography (HPLC). A shrunken-2 hybrid (cv. Illini Gold), was monitored from mid-whorl to fresh-market maturity (R3). Internodes near the base of the stalk, just below the ear, and between an ear and the tassel were sampled at each developmental stage. Chemical shifts in $\mathrm{C}$-nmr spectra were measured in parts per million hertz (ppm) down-field relative to tetramethyl silane. Through silk emergence (R1) C-nmr spectra were similar regardless of internode, having line positions between 60 and $105 \mathrm{ppm}$. Unique lines for glucose, fructose, and sucrose were at 96, 98, and $104 \mathrm{ppm}$, respectively, and mole fractions were similar to those determined by HPLC. The highest concentrations were recorded at $\mathrm{R} 1$ for sucrose $\left(26.1 \mathrm{mg} \cdot \mathrm{mL}^{-1}\right)$, from tasseling (VT) through R3 for fructose (avg. $30.4 \mathrm{mg} \cdot \mathrm{mL}^{-1}$ ), and from VT to R1 for glucose (avg. 32 $\mathrm{mg} \cdot \mathrm{mL}^{-1}$ ). Carbon-13 nuclear magnetic resonance spectroscopy can be used, with minimal sample handling, to monitor sugar concentrations in sweet corn.
\end{abstract}

Marketability of hybrid sweet corn is, in part, dependent on sugar content in kernels (Boyer and Shannon, 1983). Sugars are produced in leaves, pass through the vascular system to support physiological processes, and are deposited in kernels. Sugar transport may be interrupted and sugar deposition in kernels affected if plant development is compromised. In field corn, stem storage carbohydrates increase during early grain fill, and can be remobilized to be deposited in grain (Fairey and Daynard, 1978; Hume and Campbell, 1972). However, processes occur in the plant before grain fill that could affect sugar transport. For example, stalk internode senescence spreads rapidly at anthesis in both field and

Received for publication on 23 Dec. 1997. Accepted for publication on 30 Apr. 1998. We thank Julie Collins and Sheila Magby for assistance in the preparation of samples for HPLC analysis. Mention of a trademark, vendor, or proprietary product does not constitute a guarantee or warranty of the product by the USDA and does not imply its approval to the exclusion of other products that may also be suitable. The cost of publishing this paper was defrayed in part by the payment of page charges. Under postal regulations, this paper therefore must be hereby marked advertisement solely to indicate this fact. 'To whom reprint requests should be addressed. Email: vrusso-usda@lane-ag.org sweet corn (Pappelis and Williams, 1966; Russo and Pappelis, 1994). To what degree stalk senescence affects sugar transport is not known.

Sugar content in sweet corn has been measured by colorimetric techniques using spectroscopy and by high-performance liquid chromatography (HPLC) (Dubois et al., 1956; Engels et al., 1994; Fairey and Daynard, 1978; McBee and Maness, 1983; Somogyi, 1952; Westgate and Boyer, 1985), both of which require chemical alteration of samples. Carbon- 13 nuclear magnetic resonance spectroscopy (C-nmr) has potential as an alternative methodology for analysis of sugars.

This method is precise, accurate, and reliable, and, because of its specificity for various forms of sugars, can be used to quantify their concentrations in mixtures (Roberts et al., 1984). Although only one spectral line per sugar is used for this purpose, the numerous spectral lines, taken as a whole, can also be used to identify the sugars present. Proton$n m r$ has been used to assign D-glucose residues in starch (Laignel et al., 1997). Enzymes in corn tissue cultures, proteins in processed material from corn (Augustine and Baianu, 1986; Logan et al., 1992), and glucose metabolism in vivo in corn root tips have been studied with C-nmr (Dieuaide et al., 1991).
Determination of how environmental and cultural conditions affect transport of sugars in sweet corn would allow correlation of their effects with kernel sweetness. Monitoring sugar transport can lead to a better understanding of how sugars move through stalks and what factors affect transport. This information could lead, in turn, to a selection criterion for improved concentration of kernel sugars. Preparation of samples for $\mathrm{C}-\mathrm{nmr}$ requires minimal premeasurement handling.

This greenhouse study was undertaken to determine if C-nmr technology could be used to monitor sugars in sweet corn tissues as plants progressed from juvenile to senescent stages of development. Mole fractions determined with C-nmr were compared with those determined using HPLC.

\section{Materials and Methods}

Seeds of 'Illini Gold', a shrunken-2 sweet corn, were sown in 26-cm-diameter pots containing 11.5 L of potting soil (Redi-Earth 3CF; Grace Sierra, Milpitas, Calif.) in a greenhouse at Lane, Okla. Plants were thinned to two per pot. One liter of a soluble fertilizer, $20 \mathrm{~N}-20 \mathrm{P}-$ 20K (Scotts-Sierra, Marysville, Ohio), was applied biweekly to each pot. Plants were arranged in a randomized complete-block design with three replications (blocks).

Ritchie and Hanway (1982) described the development of the corn plant with vegetative stages based on placement of the leaf from emergence (VE, no leaves) to tasseling (VT). Reproductive stages were from silking (R1) to physiological maturity (R6). They also numbered the nodes and internodes in stalks beginning with those at the base of the plant, but not the soil line. Plants were harvested at $1100 \mathrm{HR}$ at the developmental stages of mid-whorl (V9), VT, R1, and R3, as categorized by Ritchie and Hanway (1982). This is the time of day when stem sugar levels should be highest (Stewart et al., 1997). The R3 stage, which corresponds to fresh-market maturity, occurred at $18 \mathrm{~d}$ postanthesis. Internodes near the stalk base (I7), below the ear (19), and between the ear and the tassel (I11) were sampled at each developmental stage using both plants in three pots in each block.

Internodes were split lengthwise. After the rind, which comprises the epidermis and several layers of schlerenchyma cells (Esau, 1977), was removed, sap was expressed from half of each of the fresh internodes. Samples from individual internodes were centrifuged for $5 \mathrm{~min}\left(9000 \mathrm{~g}_{\mathrm{s}}\right)$ and the supernatant was placed in 5-mm-diameter $\times 178$-mm-long cuvettes without additional preparation. A Chemagnetics A-200 (4.7 Tesla) C-nmr (Varian Chemagnetics Division, Ft. Collins, Colo.), resonating carbon-13 at $50.478 \mathrm{MHz}$, was used for analysis. Samples were left in the instrument for $16 \mathrm{~h}$ at $20^{\circ} \mathrm{C}$ for signal averaging, which amounted to 6300 acquisitions. Samples were examined at $4,8,12$, and $16 \mathrm{~h}$ to determine if sample degradation had occurred. Line positions (chemical shifts), were measured in parts per million hertz (ppm) downfield, relative to tetramethyl silane. Pure refer- 
ence substances of D-isomers of glucose, fructose, and sucrose were added to specimens to confirm the coincidence of C-nmr lines.

Quantification of spectra was based on three widely resolved down-field lines for glucose, fructose, and sucrose by taking line integrals (height $\times$ width at half maximum) as proportional to molar quantity. Calibrations of relative line areas to obtain moles per unit area were based on the relative line integrals of spectra of known mixtures of glucose, fructose, and sucrose. Line integrals were measured and subset mole fractions calculated. Subsets included only glucose, fructose, and sucrose. Normally, mole fraction is defined as the ratio of moles of a given solute to total moles present, including the solvent, but the C-nmr spectrometer detects primarily glucose, fructose, and sucrose, with only traces of other substances visible in the spectra. Subset mole fractions are defined on those three components and nothing else. Equations [5] and [6] below are specific, exact derivations describing the three component system.

For glucose, the subset mole fraction in the stalk fluid was:

$$
\mathrm{X}_{\mathrm{g}(1)}=\mathrm{g}_{1} /\left(\mathrm{s}_{1}+\mathrm{f}_{1}+\mathrm{g}_{1}\right)
$$

where $s_{1}, f_{1}$, and $g_{1}$ were the moles of sucrose, fructose, and glucose, respectively, calculated from the relative line areas. Values of $X_{s(1)}$ and $\mathrm{X}_{\mathrm{t}(1)}$ are similarly defined. A program in BASIC was used to calculate mole fractions from the relative areas of the resonances and the line calibration values.

In an nmr measurement, quantification of absolute amounts of substances present is best accomplished by adding a known amount of a substance of interest and noting the increase of its subset mole fraction. If the concentration of glucose in the spiked sample were increased by an amount $g_{2}$, its subset mole fraction would be:

$$
X_{g(2)}=\left(g_{1}+g_{2}\right) /\left(s_{1}+f_{1}+g_{1}+g_{2}\right)
$$

Equation [1] was arranged as:

$$
\mathrm{g}_{1}\left(1-\mathrm{X}_{\mathrm{g}(1)}\right)=\mathrm{X}_{\mathrm{g}(1)}\left(\mathrm{s}_{1}+\mathrm{f}_{1}\right)
$$

and Eq. [2] was written as follows:

$$
\mathrm{s}_{1}+\mathrm{f}_{1}=\mathrm{g}_{1}\left(1-\mathrm{X}_{\mathrm{g}(2)}\right) /\left(\mathrm{X}_{\mathrm{g}(2)}-\mathrm{g}_{2}+\mathrm{g}_{2} / \mathrm{X}_{\mathrm{g}(2)}\right) \text { [4] }
$$

An expression for $g_{1}$ was derived by substituting Eq. [4] $\left(s_{1}+f_{1}\right)$ into Eq. [3], where it may be shown that:

$$
\mathrm{g}_{1}=\mathrm{g}_{2} \mathrm{X}_{\mathrm{g}(1)}\left(1-\mathrm{X}_{\mathrm{g}(2)}\right) /\left(\mathrm{X}_{\mathrm{g}(2)}-\mathrm{X}_{\mathrm{g}(1)}\right)
$$

This equation was verified by two methods of manual derivation and with a symbolic mathematical processor (Maple V Release 2, MathSoft, Inc., Cambridge, Mass.). Equation [5] was valid for the conditions $\mathrm{X}_{\mathrm{g}(1)}<\mathrm{X}_{\mathrm{g}(2)}<$ 1 , and all independent variables were easily measured. The sample volume and $\mathrm{g}_{1}$ obtained in this manner permitted calculation of the concentration of glucose $[\mathrm{g}]$ in the original stalk fluid. The concentrations $\left(\mathrm{mg} \cdot \mathrm{mL}^{-1}\right)$ of the other sugars follow from their measured mole fractions; e.g., for sucrose and fructose:

$$
[\mathrm{s}]=[\mathrm{g}] \mathrm{X}_{\mathrm{s}(1)} / \mathrm{X}_{\mathrm{g}(1)} \text { and }[\mathrm{f}]=[\mathrm{g}] \mathrm{X}_{\mathrm{f}(1)} / \mathrm{X}_{\mathrm{g}(1)}[6]
$$

Separate additions of fructose and glucose were not necessary.

HortScience, Vol. 33(6), October 1998
For the other half of the internode the rind was similarly removed. The pith tissue was lyophilized, pulverized in a mortar and pestle, and frozen in plastic vials prior to analysis with HPLC. Dry samples $(0.1 \mathrm{~g})$ were extracted three times in 95\% ethyl alcohol according to the methods of McBee and Maness (1983) and brought to a final volume of $25 \mathrm{~mL}$ in triplicate for each treatment; a 1 -mL portion was dried in a test tube and held at $0{ }^{\circ} \mathrm{C}$ to await HPLC analysis.

The HPLC system consisted of a Dionex Bio LC system with a gradient pump module, a pulsed electrochemical detector, and an AI450 data station (Dionex Corp., Sunnyvale, Calif.). A Carbopac PA-1, 4-mm $\times 250-\mathrm{mm}$ column, also from Dionex, was used for separations under isocratic conditions of $92 \%$ water and $8 \% 0.5 \mathrm{~m}$ aqueous $\mathrm{NaOH}$. Samples from each extraction were dissolved in $1 \mathrm{~mL}$ of water and diluted appropriately for injection onto the HPLC. A $50-\mu \mathrm{L}$ sample was introduced onto the system by overfilling a 50 $\mu \mathrm{L}$ loop, and separations were conducted at a flow rate of $1 \mathrm{~mL} \cdot \mathrm{min}^{-1}$. Glucose, fructose, and sucrose were identified by co-elution with authentic standards, and quantified using a 2 nм standard. Levels of sugars were expressed as mole fractions.

The experimental design was a split-plot with technology used being the main plot and developmental stage the split-plot, with internode nested in the developmental stage. Each sample was replicated three times. Data were analyzed with analysis of variance (ANOVA). Main effect means were separated by Duncan's multiple range test, and the appropriate interaction means with Least Squares Means in the general linear models procedures (SAS Institute, 1996).

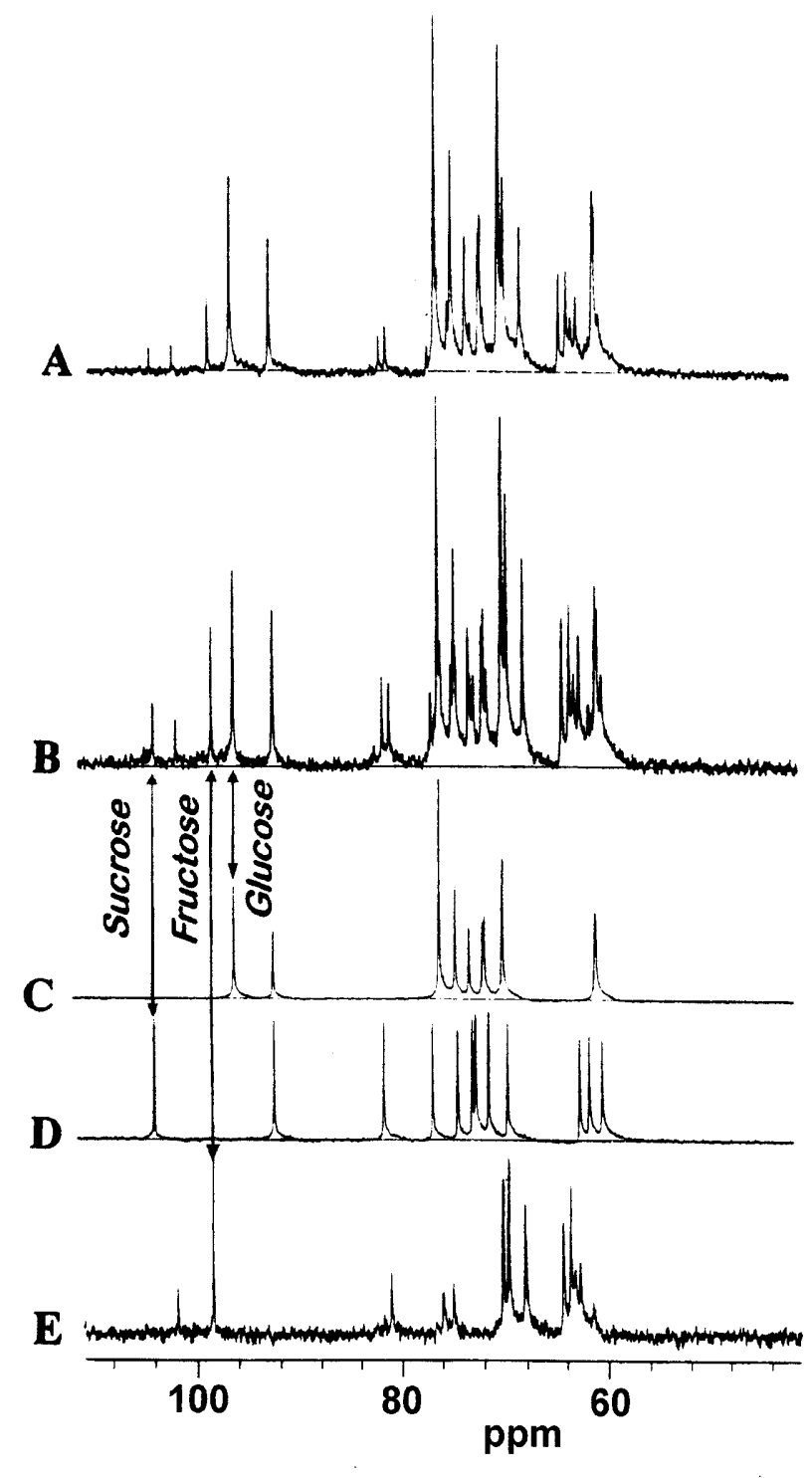

Fig. 1. C-nmr spectra of sucrose, fructose, and glucose in sap expressed from an R1-stage sweet corn internode sample, which was representative of spectra from V9 to R3, regardless of internode. The vertical double-ended arrows mark distinct lines, left to right, of sucrose, fructose, and glucose, which were used for the quantification of the proportions and concentrations of sugars. (A) R I-stage internode sample to which pure glucose had been added; (B) the same sample before adding glucose; (C) glucose alone; (D) sucrose alone; and (E) fructose alone. 


\section{Results and Discussion}

Samples did not degrade over the 16-h period while in the C-nmr spectrophotometer, indicating that the final spectra were true indicators of results. Samples yielded slightly broadened spectra, but line resolutions at characterizing resonances for glucose, fructose, and sucrose were similar to those for aqueous solutions of these sugars. Spectra for all internodes were similar through R3, having lines between 60 and 105 ppm. For aqueous solutions, unique lines at 96,98, and 104 ppm were confirmed for glucose, fructose, and sucrose, respectively, and matched to corresponding resonances in the expressed specimens (Fig. 1). With C-nmr the relative areas of wellresolved spectral lines, e.g., one from each saccharide, are used to achieve quantification of the mixture. The remaining lines in the spectra are not ignored, since they serve to confirm the identity of the substances in the mixture, something that HPLC alone cannot do.

The ANOVA analysis indicated that most main effects and interactions, including the highest order interaction Technology $\times$ Developmental stage $\times$ Internode, were significant (Table 1). Values for mole fractions of sugars were similar (Table 2). Although some differences existed, they were not consistent. This suggests that both technologies were similar in their analytical efficacy. The C-nmr quantification of glucose, fructose, and sucrose in expressed internode sap was comparable to quantification by HPLC. However, C-nmr is more specific for chemical substances than is HPLC. A C-nmr spectrum of a compound will contain as many unique resonance lines as there are distinct symmetry environments in the molecule, and the resolution of the method (line width vs. spectrum width) is high (Wright et al., 1986). Direct spectroscopic quantification of individual compounds is difficult in complex mixtures. However, when the number of components present is low $(<5$, as was the case in this project), high-resolution spectroscopic methods, such as C-nmr, are suitable for analytical applications.

Developmental stage affected concentration of sugars as determined by C-nmr, but only the concentration of glucose varied with internode position, and there was no developmental stage $\times$ internode interaction (Table 3 ). The concentration of sucrose was highest at $\mathrm{R} 1$, that of fructose increased from V9 to VT, then stabilized, and that of glucose increased between V9 and VT and decreased between $\mathrm{R} 1$ and R3. Average concentrations of sucrose and fructose were 12.3 and $27.5 \mathrm{mg} \cdot \mathrm{mL}^{-1}$ for all internodes, and concentrations of glucose were similar for I7 and I9 and increased in I1 1 .

Other studies examining sugar concentrations in sweet corn have been primarily confined to kernels (Doehlert and Kuo, 1994; Doehlert et al., 1988; Ferguson et al., 1979). However, concentrations of sucrose and total sugars in entire stalks of field corn have been measured over developmental stages, and found to change with variety (Fairey and

Table 1. Significance of $F$ values for main effects and interactions following ANOVA of data for concentrations of sugars in three sweet corn internodes at four developmental stages, as determined by C-nmr and HPLC.

\begin{tabular}{lccr}
\hline & \multicolumn{3}{c}{ Mole fraction } \\
\cline { 2 - 4 } Source & Sucrose & Fructose & Glucose \\
\hline Technology & 0.0001 & 0.6324 & 0.0001 \\
Developmental stage & 0.0001 & 0.0001 & 0.0001 \\
Internode & 0.0001 & 0.0001 & 0.5971 \\
Technology $\times$ developmental stage & 0.0002 & 0.0021 & 0.7393 \\
Technology $\times$ internode & 0.5501 & 0.0024 & 0.0001 \\
Developmental stage $\times$ internode & 0.0061 & 0.0054 & 0.0162 \\
Technology $\times$ developmental stage $\times$ internode & 0.0349 & 0.0289 & 0.0011 \\
Replication & 0.5805 & 0.7032 & 0.8382 \\
\hline
\end{tabular}

Table 2. Effects of the developmental stage $\times$ internode tested $\times$ technology used for analysis of mole fractions of sucrose, fructose, and glucose in sweet corn.

\begin{tabular}{|c|c|c|c|c|c|}
\hline \multirow{2}{*}{$\begin{array}{l}\text { Developmental } \\
\text { stage }\end{array}$} & \multirow[b]{2}{*}{ Internode } & \multirow[b]{2}{*}{ Technology } & \multicolumn{3}{|c|}{ Mole fraction } \\
\hline & & & Sucrose & Fructose & Glucose \\
\hline \multirow[t]{4}{*}{$\overline{V 9}$} & 7 & C-nmr & 0.000 & 0.420 & 0.580 \\
\hline & & HPLC & $0.006^{\lll /}$ & 0.474 ss & $0.520^{\star s}$ \\
\hline & 9 & C-nmr & 0.000 & 0.460 & 0.540 \\
\hline & & HPLC & $0.003^{\star s}$ & $0.480^{\aleph}$ & $0.517^{\text {s }}$ \\
\hline \multirow[t]{6}{*}{ VT } & 7 & C-nmr & 0.077 & 0.403 & 0.520 \\
\hline & & HPLC & $0.189^{m}$ & $0.367^{\star s}$ & $0.444^{\prime \prime}$ \\
\hline & 9 & C-nmr & 0.084 & 0.417 & 0.503 \\
\hline & & HPLC & $0.133^{` s}$ & $0.418^{\aleph \varsigma}$ & $0.449^{k \prime}$ \\
\hline & 11 & C-nmr & 0.017 & 0.453 & 0.530 \\
\hline & & HPLC & $0.029^{\prime \prime}$ & $0.490^{\mathrm{s}}$ & $0.481^{\Perp}$ \\
\hline \multirow[t]{6}{*}{$\mathrm{R} 1$} & 7 & C-nmr & 0.167 & 0.393 & 0.443 \\
\hline & & HPLC & $0.301^{3}$ & $0.323^{\mathrm{k}}$ & $0.376^{*}$ \\
\hline & 9 & C-nmr & 0.197 & 0.420 & 0.387 \\
\hline & & HPLC & $0.290^{\circ}$ & $0.327^{` s}$ & $0.366^{\star \prime}$ \\
\hline & 11 & C-nmr & 0.117 & 0.397 & 0.487 \\
\hline & & HPLC & $0.304 * *$ & $0.339^{\star s}$ & $0.356 *$ \\
\hline \multirow[t]{6}{*}{ R3 } & 7 & C-nmr & 0.120 & 0.500 & 0.380 \\
\hline & & HPLC & $0.126^{\mathrm{is}}$ & $0.493^{\text {ss }}$ & $0.378^{\lll}$ \\
\hline & 9 & C-nmr & 0.007 & 0.617 & 0.373 \\
\hline & & HPLC & $0.004^{* s}$ & 0.584 & $0.415^{\star s}$ \\
\hline & 11 & C-nmr & 0.000 & 0.560 & 0.444 \\
\hline & & HPLC & $0.004^{* s}$ & 0.786 & 0.213 \\
\hline
\end{tabular}

"Nonsignificant or significant at $P \leq 0.05$ and 0.01 , respectively, by Least Squares Means analysis.

Daynard, 1978; Westgate and Boyer, 1985). The percentages of sucrose and total sugars either increased through seed harvest, or increased and then decreased by seed harvest. Previous studies have not followed sugar distribution in internodes during development. This type of study can provide information on how sugars are metabolized and distributed within sweet corn, and how cultural practices or the environment can affect distribution. In sweet corn this is especially important since sugars are transported to kernels, and an important factor determining marketability is kernel sweetness.

When field corn plants change from the vegetative to the reproductive stages, sugars move from the leaves and stems to tassels and ears, and sugar content in internode tissues changes (Cliquet et al., 1990; Engels et al., 1994; Hume and Campbell, 1972). Through R3 the plant continued to absorb water and active transport occurred, but the tissues through which transport occurs are undergoing senescence (Russo and Pappelis, 1994). Between R1 and R3, sugars may be transported to the kernels as glucose, fructose, or sucrose. Beginning with R3, changes occur that ultimately result in maturation of kernels and culminate in death of the plant. As senes-
Table 3. Main effects of developmental stage and internode sampled on concentrations of sugars in sweet corn as determined by C-nmr.

\begin{tabular}{lrrr}
\hline & \multicolumn{3}{c}{ Concentration $\left(\mathrm{mg} \cdot \mathrm{mL}^{-1}\right)$} \\
\cline { 2 - 4 } Treatment & Sucrose & Fructose & Glucose \\
\hline Developmental & & & \\
stage & & & \\
$\quad$ V9 & $0.0 \mathrm{~b}^{2}$ & $13.9 \mathrm{~b}$ & $15.3 \mathrm{c}$ \\
VT & $7.5 \mathrm{~b}$ & $31.6 \mathrm{a}$ & $32.4 \mathrm{a}$ \\
R1 & $26.1 \mathrm{a}$ & $27.6 \mathrm{a}$ & $31.5 \mathrm{a}$ \\
R3 & $7.5 \mathrm{~b}$ & $32.1 \mathrm{a}$ & $23.3 \mathrm{~b}$ \\
Internode & & & \\
$\quad 7$ & $16.0 \mathrm{a}$ & $24.0 \mathrm{a}$ & $25.0 \mathrm{~b}$ \\
9 & $12.2 \mathrm{a}$ & $28.1 \mathrm{a}$ & $24.8 \mathrm{~b}$ \\
11 & $8.7 \mathrm{a}$ & $30.5 \mathrm{a}$ & $33.9 \mathrm{a}$ \\
\hline
\end{tabular}

'Mean separation within stages and internodes by Duncan's multiple range test $(P \leq 0.05), \mathrm{N}=9$. Stage $\times$ internode interaction was nonsignificant.

cence spreads through plant tissues, the movement of sugars may be restricted. However, this has not been determined.

Concentrations of sugars in tissues are dependent, in part, on the genetic makeup and nutritional status of the plant and/or environmental conditions. The $\mathrm{C}-\mathrm{nmr}$ technique can be used to provide information on sugar distribution in sweet corn stalks. A major advantage of C-nmr is that there is little physical, and, in 
this application, no chemical, preanalysis preparation of samples in expressed sap. This technology should provide an additional tool for better understanding of sugar metabolism in high quality sweet corn.

\section{Literature Cited}

Augustine, M.E. and I.C. Bainau. 1986. High-resolution carbon-13 nuclear magnetic resonance studies on maize protein. J. Cereal Sci. 4:371378.

Boyer, C.D. and J.C. Shannon. 1983. The use of endosperm genes for sweet corn improvement. Plant Breeding Rev. 5:139-161.

Cliquet, J.-B., E. Deleens, A. Bousser, M. Martin, J.C. Lescure, J.-L. Prioul, A. Mariotti, and J.-F. Morot-Gaudry. 1990. Estimation of carbon and nitrogen allocation during stalk elongation by ${ }^{13} \mathrm{C}$ and ${ }^{15} \mathrm{~N}$ tracing in Zea mays L. Plant Physiol. 92:79-87.

Dieuaide, M., P. Raymond, G. Raffard, P. Canioni, and A. Pradet. 1991. NMR study of glucose metabolism in excised maize root tips, p. 133. In: Y. de Kouchkovsky (ed.). Colloques de l'Inra, No. 59. Plant sciences today: First general colloquium on plant sciences, La Colle Sur Loup, France. Inst. Natl. Rech. Agron., Paris.

Doehlert, D.C. and T.M. Kuo. 1994. Gene expression in developing kernels of starch-deficient endosperm mutants of maize. Plant Cell Physiol. 35:411-418.

Doehlert, D.C., T.M. Kuo, and F.C. Felker. 1988.
Enzymes of sucrose and hexose metabolism in developing kernels of two inbreds of maize. Plant Physiol. 86:1013-1019.

Dubois, M., K.A. Gilles, J.K. Hamilton, P.A. Rebers, and F. Smith. 1956. Colorimetric method for determination of sugars and related substances. Anal. Chem. 28:350-356.

Engels, C., B. Buerkert, and H. Marschner. 1994. Nitrogen and sugar concentrations in the xylem exudate of field-grown maize at different growth stages and levels of nitrogen fertilization. Europ. J. Agron. 3:197-204.

Esau, K. 1977. Anatomy of seed plants. 2nd ed. Wiley, New York.

Fairey, N.A. and T.B. Daynard. 1978. Quantitative distributions of assimilates in component organs of maize during reproductive growth. Can. J. Plant Sci. 58:709-717.

Ferguson, J.E., D.B. Dickinson, and A.M. Rhodes. 1979. Analysis of endosperm sugars in a sweet corn inbred (Illinois 677a) which contains the sugary enhancer (se) gene and comparison of se with other corn genotypes. Plant Physiol. 63:416420.

Hume, D.J. and D.K. Campbell. 1972. Accumulation and translocation of soluble solids in corn stalks. Can. J. Plant Sci. 52:363-368.

Laignel, B., C. Bliard, G. Massiot, and J.M. Nuzillard. 1997. Proton NMR spectroscopy assignment of D-glucose residues in highly acetylated starch. Carbohydrate Res. 298:251-260.

Logan, T.M., P. Zhong, and D.G. Lynn. 1992. Metabolic thermotolerance: Magnetic resonance detected protection of glutamate synthase. Bio- chemistry 31:7256-7263.

McBee, G.G. and N.O. Maness. 1983. Determination of sucrose, glucose and fructose in plant tissues by high-performance liquid chromatography. J. Chromatography 264:474-478.

Pappelis, A.J. and J.R. Williams. 1966. Patterns of cell death in elongating corn stalks. Trans. Illinois State Acad. Sci. 59:195-198.

Ritchie, S. and J.J. Hanway. 1982. How a corn plant develops. Spec. Rpt. 48, Iowa State Univ., Ames.

Roberts, J.K.M. 1984. Study of plant metabolism in vivo using NMR spectroscopy. Annu. Rev. Plant Physiol. 35:375-386.

Russo, V.M. and A.J. Pappelis. 1994. Cell death patterns in stalks of a "supersweet" sweet corn cultivar. HortScience 29:919.

SAS Institute. 1996. SAS/STAT user's guide, release 6.1 ed. SAS Inst., Cary, N.C.

Somogyi, M. 1952. Notes on sugar determination. J. Biol. Chem. 195: 19-23.

Stewart, D.W., L.M. Dwyer, C.J. Andrews, and J.A. Dugas. 1997. Modeling carbohydrate production, storage, and export in leafy and normal maize (Zea mays L.). Crop Sci. 37:1228-1236.

Westgate, M.E. and J.S. Boyer. 1985. Carbohydrate reserves and reproductive development at low leaf water potentials in maize. Crop Sci. 25:762769.

Wright, J.R., W.A. Hendrickson, S. Osaki, and G.T. James. 1986. Physical methods for inorganic biochemistry, p. 1-115. In: E. Frieden (series ed.). Biochemistry of the elements. vol. 5. Plenum, New York. 